\title{
At the epicenter of severe acute respiratory syndrome
}

\author{
Song Wan, MD, PhD \\ Anthony P. C. Yim, MD
}

From the Division of Cardiothoracic Surgery, Department of Surgery, The Chinese University of Hong Kong, Prince of Wales Hospital, Hong Kong, People's Republic of China.

Received for publication Feb 24, 2004; accepted for publication March 1, 2004.

Address for reprints: Song Wan, MD, PhD, Division of Cardiothoracic Surgery, Department of Surgery, Prince of Wales Hospital, The Chinese University of Hong Kong, Shatin, Hong Kong, People's Republic of China (E-mail: swan@cuhk.edu.hk).

J Thorac Cardiovasc Surg 2004;127:1553-7 $0022-5223 / \$ 30.00$

Copyright $\odot 2004$ by The American Association for Thoracic Surgery

doi:10.1016/j.jtcvs.2004.03.002
Each person is born to one possession which outvalues all his others-his last breath.

-Mark Twain

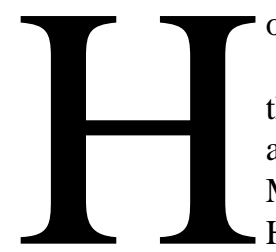

ong Kong will take your breath away!"

This simple slogan, used by the Hong Kong Tourism Board at the beginning of 2003, took a different meaning when severe acute respiratory syndrome (SARS) hit Hong Kong in early March. ${ }^{1,2}$ Over the following 3 months, 1755 cases emerged in Hong Kong, with a crude fatality rate of $17 \% .^{3}$ In the same period worldwide, SARS affected more than 8400 persons and claimed more than 900 lives. ${ }^{3-5}$ It was estimated by the Asian Development Bank that the SARS-related financial loss in Asia reached US $\$ 59$ billion (about 5 times as high as that after the September 11 tragedy). Peculiarly but sadly, SARS is probably one of the few diseases that rapidly attacks health care professionals in the first place (Table 1). In Hong Kong alone, 386 health care workers came down with this new disease. Many of them, including one of the authors (S.W.), were young and previously healthy individuals.

Needless to say, SARS has profoundly changed our lives in this part of the world. When Dr Wechsler first invited us to write this special article for the Journal, we decided to approach such a subject not so much from a scientific viewpoint but rather from a personal perspective. We would like to share with our cardiothoracic surgical colleagues around the world how this disease affected us and, in particular, our perspective to medicine.

\section{S. Wan: Life-Threatening Experience}

Recent statistics have shown that more than $80 \%$ of the Hong Kong health care workers who contracted SARS in 2003 were actually infected before the end of March 2003, when the world had little knowledge about this disease.

I was one of them. The syndrome was first named by the World Health Organization, with an emergency travel advisory put in place on March $15,{ }^{3}$ which was already the second day of my intensive care unit (ICU) stay and about a week after my colleagues and I went to ward 8A for an apparently ordinary cardiology consultation.

The patient we saw on March 7 was staying next to the index SARS patient at Prince of Wales Hospital. ${ }^{2}$ The use of nebulizer therapy on that index patient was not identified as the key factor contributing to the extensive spread of the infection in ward 8A until the evening of March 14. Eventually, 143 individuals, including 50 health care workers, 17 medical students, 30 patients, 42 visitors, and the index patient's own 4 relatives, acquired the infection through direct contact with this 26-year-old man. ${ }^{3}$

After the visit to ward 8A, I became sick over the weekend with flu-like symptoms, such as diarrhea, malaise, and myalgia, which developed gradually. Three doses of intravenous augmentin ( $1.2 \mathrm{~g}$ per 8 hours) were given to me on Monday, March 10, which brought no benefit. With some doubts in mind, I went to obtain a chest x-ray film for myself on Tuesday. In view of the radiologic evidence of "pneumonia" (Figure 1, A), I was immediately admitted to the hospital by my 
TABLE 1. Summary data of global SARS cases (November 2002 through August 2003)

\begin{tabular}{lcc}
\hline Country or region & $\begin{array}{c}\text { Cumulative total of } \\
\text { SARS cases/deaths }\end{array}$ & $\begin{array}{c}\text { Health care workers } \\
\text { infected } \% \text { of total) }\end{array}$ \\
\hline Mainland China & $5327 / 349$ & $1002(19)$ \\
Hong Kong SAR, China & $1755 / 300$ & $386(22)$ \\
Taiwan, China & $665 / 180$ & $86(13)$ \\
Canada & $251 / 41$ & $108(43)$ \\
Singapore & $238 / 33$ & $97(41)$ \\
Vietnam & $63 / 5$ & $36(57)$ \\
Others & $123 / 8$ & Not available \\
\hline
\end{tabular}

Source: World Health Organization Web site (as of August 15, 2003). Consensus document on the epidemiology of severe acute respiratory syndrome (SARS). Available at http://www.who.int/csr/sars/en/WHOconsensus.pdf. Accessed November 15, 2003

chief (A.Y.). In the evening after admission, I started to have a persistently high temperature reaching $39.8^{\circ} \mathrm{C}$ despite intravenous clarithromycin and cefotaxime. With rapidly increasing respiratory distress, my oxygen saturation decreased significantly to as low as $92 \%$, and nasal oxygen supplementation soon became necessary.

Unfortunately, I was not alone. On the following day, 23 of the 50 sick staff members in our hospital (15 had temperatures of greater than $38^{\circ} \mathrm{C}$, and the remaining $8 \mathrm{had}$ signs of pneumonia on chest x-ray films) were isolated in an observation ward that had an independent air-exchanging system. ${ }^{3}$ In fact, our infection-control colleagues worried that this kind of rapid spread of a killer virus could represent a bioterrorism attack. Retrospectively, however, such a preemptive move obviously augmented the chance of crossinfection among us. Exactly 24 hours later, I had to be transferred to our ICU from this observation ward because my condition worsened. The previous two antibiotics were replaced with levofloxacin, but my high fever was unaffected. Hydrocortisone and an antiviral agent, ribavirin, were then administered in the evening. Although the use of steroids and ribavirin in treating SARS still remains controversial, it appeared somewhat beneficial in my case because my body temperature returned to normal 12 hours later and never increased thereafter. Nevertheless, my respiratory function continued to deteriorate in the next few days. Even with a $100 \%$ oxygen mask, my saturation could only barely reach $94 \%$. I tried my very best to stay away from mechanical ventilation, even though such an option was seriously considered on a daily basis by my ICU colleagues for most of my remaining stay in the unit.

On the afternoon of March 24, holding my horrible chest x-ray film (Figure 1, B) in his hand, Professor Joseph Sung, Chairman of the Department of Medicine and Therapeutics (who was later elected by the public to be the first of the SARS heroes in Hong Kong), offered me two last resorts: to receive either "pulse steroid" (daily 500-mg infusion of methylprednisolone) or convalescent sera (from patients who had recovered from SARS). I chose the former. Fortunately, it worked.

Having spent 16 days in the ICU, I was discharged to the isolation ward on March 29. ("Isolation" during this special period meant that I could still talk to my wife or other family members and friends through a mobile phone, which I felt quite essential for my recovery.) I was strongly encouraged that afternoon by a timely call from my teammate, Dr Innes Wan (who contracted SARS at ward 8A during the same consultation with me and also spent a week in our ICU) because he told me that he was heading home the next day. After the conversation, I immediately decided to speed up my physical exercise. To my surprise, just standing up for less than a minute increased my heart rate from 78 to 148 beats/min (even though I was wearing an oxygen mask with a flow of $6 \mathrm{~L} / \mathrm{min})$ !

Nevertheless, after a total of 6 doses of pulse steroid and vigorous chest physiotherapy, I was eventually weaned from nasal oxygen supplementation on the evening of April 4. I went back home the next morning as soon as my last chest x-ray film was reviewed (Figure 1,C). The warm farewell by my medical and nursing colleagues was complemented by some congratulations because my body weight was $10 \mathrm{~kg}$ less than 25 days earlier.

\section{S. Wan: Convalescence and Afterthoughts \\ First Things First}

During my first week home, I could hardly even lie on my side (which immediately led to breathless and tachycardia). Despite that, I felt really glad and grateful, not only because I survived, but also because I suddenly started to appreciate many small things in life that were somehow overlooked in the past. The sudden and dramatic role change from being a health care provider to becoming a recipient generated an effect greater than I could ever have anticipated. I simply cannot agree more with Dr Roger Bone's previous remarks ${ }^{6}$ :

(1) Good health is often taken for granted; however, it is the most precious commodity one possesses.

(2) One's spouse, children, family, and friends are the essential ingredients that allow one to endure an experience such as a serious and unexpected illness.

Nonetheless, at this stage, I might still have a little reservation for Dr Bone's last statement ${ }^{6}$ : "The things one does throughout one's life that seem so urgent are, most of the time, not so important."

During my ICU days, in fact, I kept reminding myself of what was said by a Chinese philosopher, Meng Zi (372-289 $\mathrm{BC})$ :

When Heaven is about to place a great burden on a man, it always tests his resolution first, exhausts his body and makes him suffer great hardships, frustrates his efforts to 

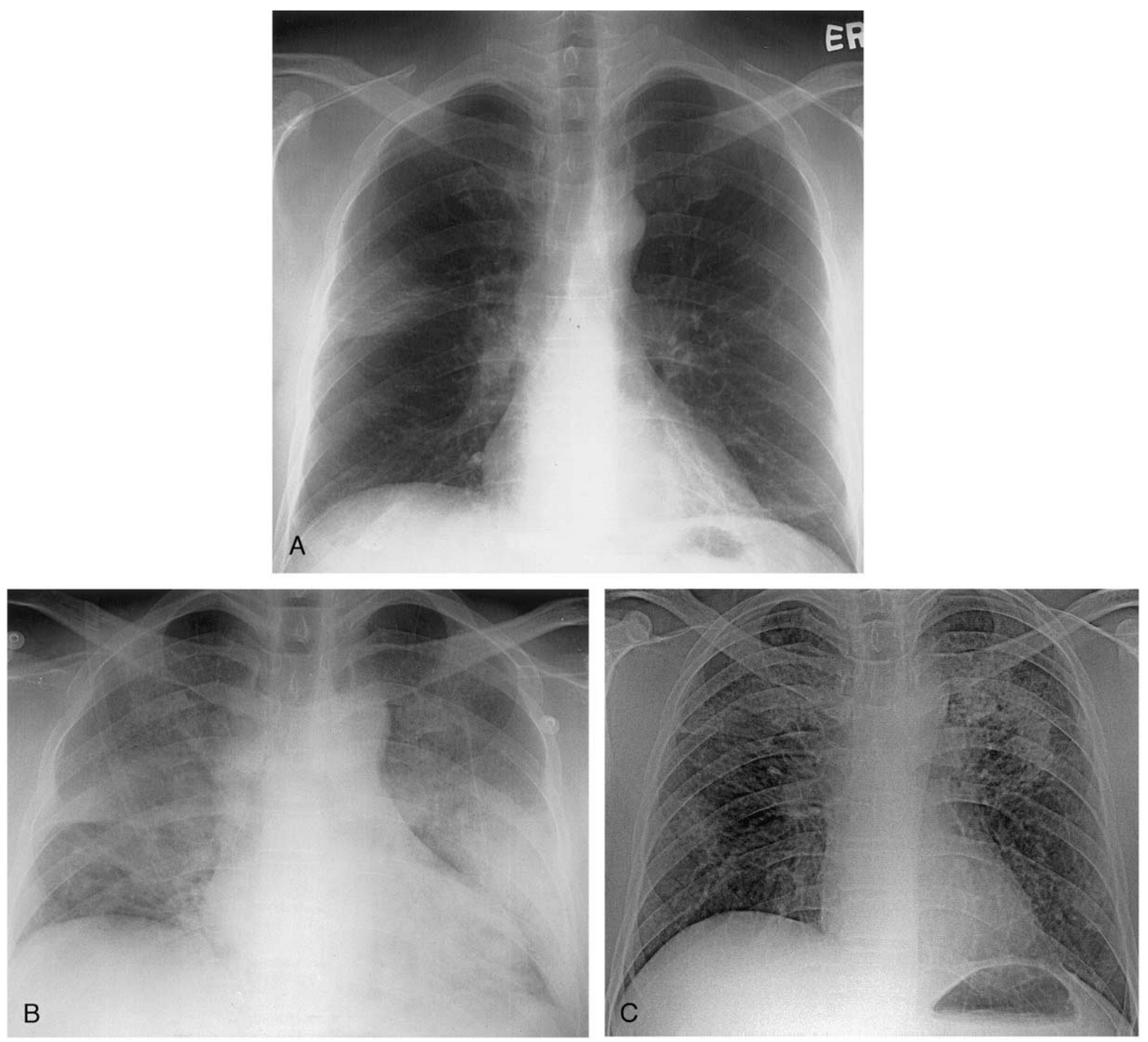

Figure 1. Dr Wan's representative chest x-ray films during his hospital stay: A, March 11, 2003; B, March 24, 2003; C, April 5, 2003.

recover from mental lassitude. Then Heaven toughens his nature and makes good his deficiencies.

Even though I could not freely move my body then, I had no slight doubt that as a Chinese cardiac surgeon, my "great burden" in China is still to be accomplished. At no time in my life until that very moment did I realize truly that life could be so vulnerable. This in turn led me to rethink my priorities in life.

\section{Fear: False Evidence Appearing Real?}

In the early period of the SARS epidemic, one could almost smell fear in the air. Mystic, highly contagious, and deadly, SARS has all the makings of a dreadful disease that instills fear in the public. ${ }^{3}$ Many frontline health care workers even dared not return home after work over the first few weeks after the outbreak to avoid the possible transmission of the killer virus to their loved ones.

Obviously, such a fear was partially related to the lack of knowledge then, when the exact mechanism of transmission of this newly discovered disease was unknown and its treatment was undetermined. In a sense, however, fear could be potentially good: as health care providers, we must always remember to adequately protect ourselves before helping any patient or we might ultimately help nobody.

\section{Professionalism}

I thought I knew the meaning of professionalism long ago. In the dictionary it is simply defined as "mark and qualities of a profession." While lying in the ICU bed, I had a unique opportunity to observe the remarkable professionalism of 
my colleagues and to appreciate this word repeatedly. Under the enormous pressure treating the then-unknown but potentially lethal illness and under the scrutiny of many colleagues as patients, the quiet courage, passionate dedication, and magnificent teamwork of those frontline doctors and nurses in my hospital have been deeply cherished locally and also applauded internationally. As a matter of fact, the "dirty team" at Prince of Wales Hospital, representing the frontline medical and intensive care staff, won the Time 2003 Asian Heroes Award. ${ }^{7}$

When we retrospectively examine the worldwide statistics of all health care workers who contracted SARS, a notable phenomenon is that there were significantly more nursing staff than doctors. For instance, the ratio was about 10:3 in Hong Kong. ${ }^{3}$ One of the possible explanations is that compared with a doctor, the nursing staff has more frequent direct contact with patients with SARS, often within a short distance ( $<3$ feet) and over a longer period of time, which cumulatively could increase the risk of infection. This simple fact speaks for itself that glory only comes after the invisible grunt work by every member of the team.

My personal experience has also demonstrated to me that small things can really add up. It appears to me now that dedication, hard work, and teamwork do not cover the full scope of professionalism because we are caring for patients rather than just treating disease. Respecting a patient and taking care of his or her daily needs is also of the utmost importance in terms of providing mental support to the particular patient. I will never forget the touching feeling when three ICU nurses helped me wash my hair and feet, while I was unable to even get out of bed.

\section{Treasure: Nothing Is Expensive if It Has a Price}

In the pre-SARS era, I tried my best to achieve whatever I thought was essential for a successful career, which almost monopolized all my time and energy. As a result, family activities were frequently listed low in my agenda. Although I often regretted that in the past, I believed such compromise was to be expected. The sudden attack of SARS actually taught me to see a lot of things in a different light (ie, as a patient, a friend, a father, or a husband), which helped me to realize that many so-called mundane things carry the real joy in life.

Indeed, the most valuable things in our lives, such as health, time, love, or friendship, hold some common characteristics: we can never buy them, and if we lose them, it would be extremely difficult to get them back. So the only thing we should do is to treasure them now!

\section{A. Yim: Additional Remarks}

2003 was a year few of us in Hong Kong will ever forget. Our hospital and indeed our whole health care system faced the biggest challenge ever, a challenge of an unprecedented magnitude. They were the darkest hours in the history of our hospital, but at the same time, the finest and most glorious hours of humanity. We witnessed our medical, nursing, and paramedical colleagues risking exposure to a hitherto unknown virus to save the lives of others. It was both sad and heartwarming.

March through May 2003 represented the 3 most difficult months in my professional career so far, not only because two of my closest colleagues contracted the disease, but also because I saw a service that I helped to build up come to a complete halt. As medical resources were focused to fight SARS, which included deployment of our medical and nursing staff from surgery, operations were initially slowed down and then completely stopped for almost 10 weeks, something that has never happened before in this hospital. Many surgical wards were closed, and there were endless meetings every day to deal with administrative crises. Patients with immediate life-threatening diseases, such as critical coronary artery disease and lung cancer, had to be transferred to outside hospitals for treatment. However, arrangements of such transfers are difficult at the best of times and a lot more difficult at a time of crisis, when resources everywhere were also concentrated in the battle against SARS. For the first time, we had to liaise with a nearby private hospital to have some of our public patients operated on there.

To avoid exposing my own family to the deadly virus, I chose to stay in a nearby hotel for 2 weeks. After that, my wife took our two daughters to Vancouver to stay with her mother for 3 months. It was very difficult not to be able to see my family, especially at a time of crisis, but we all understood that was the best solution under such circumstances.

\section{Summary: A Wake-up Call No One Can Afford to Ignore}

One of the most important lessons learned from this battle against SARS is that, as in all kinds of war, the victory is very much dependent on efficient communications. Regardless of political and economic concerns, absolute honesty and transparency are to be expected from the public. The outbreak of SARS rapidly spread to affect as many as 32 countries and regions. As the world is getting smaller with jet travel, no one can be immune if our neighbors are in danger. The price of covering up the outbreak of SARS was more deaths because of repeated mistakes. Hence, as an expert in crisis management once pointed out: "The bottom line of my own experience with crises can be summarized in just seven words: tell the truth and tell it fast."

In this era of information technology, many landmark scientific reports on SARS, including those investigating the epidemiologic issues, management of the disease clinically, identification of the original virus (SARS-associated coronavirus), and the sequencing of its genome, were all pub- 
lished online first and became immediately available to everyone interested. It has been clearly demonstrated throughout the SARS period that better understanding of the disease is the best recipe in relieving public panic.

The first pandemic of the 21st century has taught us a painful lesson that we simply cannot afford to forget. Although many scientific questions remain to be answered, at least one thing is clear-we can no longer remain complacent because SARS or other new infectious diseases might appear again. However, compared with where we were at the beginning of 2003, our society, and indeed the whole world, is now better prepared.

SARS serves as a wake-up call for the world. When most people thought the present medical advances had triumphed over infection, SARS bluntly reminded us that this is not the case. The current avian flu epidemic is another good case in point. No doubt there is an urgent need for heightened global awareness and alertness, and we must get ready for other new and emerging infectious diseases. Ideally, history will not repeat itself if we stick to the policy of early detection and reporting, quick verification and isolation, and effective treatment and containment. ${ }^{9-11}$

\section{References}

1. Lee N, Hui D, Wu A, Chan P, Cameron P, Joynt GM, et al. A major outbreak of severe acute respiratory syndrome in Hong Kong. $N$ Engl J Med. 2003;348:1986-94.

2. Tomlinson B, Cockram C. SARS: experience at the Prince of Wales Hospital, Hong Kong. Lancet. 2003;361:1486-7.

3. SARS expert committee. SARS in Hong Kong: from experience to action. Available at: http://www.sars-expertcom.gov.hk/english/reports. Accessed January 6, 2004.

4. World Health Organization Communicable Disease Surveillance and Response. Severe acute respiratory syndrome (SARS): status of the outbreak and lessons for the immediate future. Available at: http:// www.who.int/csr/media/sars. Accessed May 20, 2003.

5. Peiris JS, Yuen KY, Osterhaus AD, Stohr K. The severe acute respiratory syndrome. N Engl J Med. 2003;349:2431-41.

6. Bone RC. The taste of lemonade on a summer afternoon. JAMA. 1995;273:518.

7. Green W. Time Asian heroes 2003. Time. 2003;161(16):32-3.

8. Augustine NR. Managing the crisis you tried to prevent. In: Harvard business review on crisis management. Boston: Harvard Business School Press; 2000. p. 1-31.

9. Zhong NS, Zeng GQ. Our strategies for fighting severe acute respiratory syndrome (SARS). Am J Respir Crit Care Med. 2003;168:7-9.

10. Chinese Medical Association. Consensus for the management of severe acute respiratory syndrome. Chin Med J. 2003;116:1603-36.

11. Low DE, McGeer A. SARS—one year later. $N$ Engl J Med. 2003; 349:2381-2.

Access to The Journal of Thoracic and Cardiovascular Surgery Online is reserved for print subscribers!

Full-text access to The Journal of Thoracic and Cardiovascular Surgery Online is available for all print subscribers. To activate your individual online subscription, please visit The Journal of Thoracic and Cardiovascular Surgery Online, point your browser to http://www.mosby.com/jtcvs, follow the prompts to activate your online access, and follow the instructions. To activate your account, you will need your subscriber account number, which you can find on your mailing label (note: the number of digits in your subscriber account number varies from 6 to 10). See the example below in which the subscriber account number has been circled:

\section{Sample mailing label}

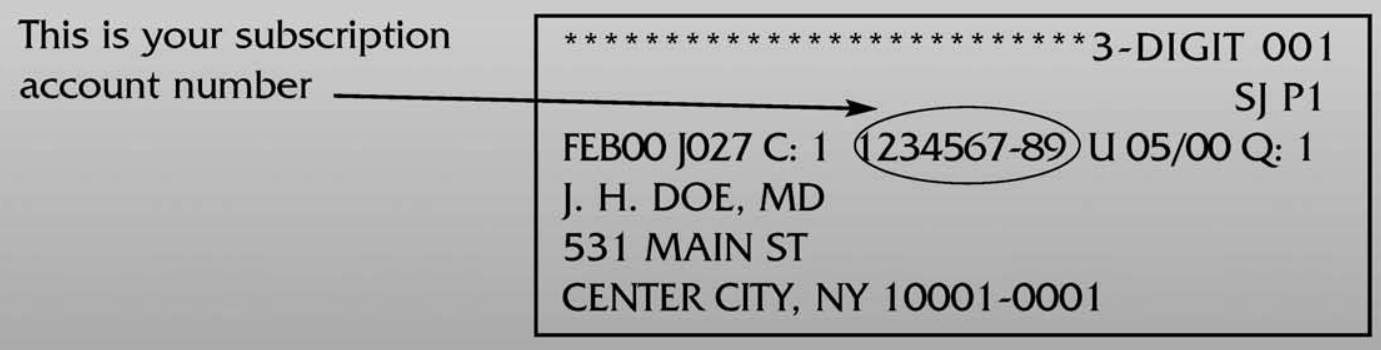

Personal subscriptions to The Journal of Thoracic and Cardiovascular Surgery Online are for individual use only and may not be transferred. Use of The Journal of Thoracic and Cardiovascular Surgery Online is subject to agreement to the terms and conditions as indicated online. 